\title{
KUALITAS PAPAN KOMPOSIT YANG TERBUAT DARI LIMBAH KAYU SENGON DAN KARTON DAUR ULANG
}

\author{
The Quality of Composite Board Made From Sengon Wood Wastes \\ and Recycled Carton
}

Suhasman, Muh. Yusram Massijaya, Yusuf Sudo Hadi

\begin{abstract}
The use of recycled carton as an alternative material for the layer of composite board may increase the board strength properties. The objective of this research was to find out the influence of face and back layer types on the quality of produced boards. Materials used in this study were wafer made from sengon wood (Paraserianthes falcataria L. Nielsen), water based polymer isocyanate adhesive, and several kinds of cartons such as duplex carton, recycled carton, and waste of corrugated board. The composite board was produced with the target density of $0.65 \mathrm{~g} / \mathrm{cm}^{3}$ and the resin solid content of $6 \%$ based on oven dry weight of particle, face and back layers. The results are as follows : 1) Utilization of carton layers improved the dimensional stability and bending strength of board; 2) Composite board with recycled carton layer fullfilled the Japanese Industrial Standard (JIS) A-5908-1994 for wafer board type in terms of density, water content, and modulus of rupture (MOR) in lengthwise and widhtwise of board but, did not fullfill that for veneered particled board type; 3 ) The presence of those layer material types decreased internal bond of the board.
\end{abstract}

Keywords : composite board, face and back layer types, recyled carton

\section{PENDAHULUAN}

Salah satu jenis papan komposit yang memiliki kekuatan mekanis yang tinggi adalah com-ply. Kekuatan com-ply yang tinggi terutama disebabkan oleh keberadaan lapisan finir yang memiliki kekuatan tarik tinggi. Namun demikian, akibat semakin terbatasnya suplai bahan baku kayu untuk pembuatan finir, maka inovasi teknologi untuk memanfaatkan limbah atau bahan daur ulang sebagai bahan substitusi finir perlu terus dikembangkan.

Penelitian untuk meningkatkan kualitas papan komposit telah dilakukan oleh beberapa peneliti. Massijaya (1997; 2003) menggunakan lapisan kertas pada papan partikel limbah kertas koran dan lapisan karton gelombang pada papan wafer untuk meningkatkan kualitas papan. Sudijono dan Subiyakto (2002) menggunakan bilah bambu sebagai bahan pelapis papan partikel, sementara Hayashi et al., (2003) menggunakan papan serat berkerapatan sedang (medium density fiberboard) sebagai pelapis papan partikel gelombang. Hasil-hasil penelitian tersebut menunjukkan bahwa penggunaan bahan pelapis alternatif tersebut dapat memperbaiki sifat mekanis papan komposit.
Bahan pelapis alternatif yang belum dicoba penggunaannya adalah karton daur ulang. Dengan konsumsi kertas di Indonesia sebesar 23,6 $\mathrm{kg} / \mathrm{kapita} / \mathrm{tahun}$ (Mansur, 2002), maka potensi limbah kertas sebagai bahan produk daur ulang cukup besar. Saat ini, beberapa jenis karton yang merupakan produk daur ulang telah banyak beredar di pasaran. Karton daur ulang tersebut dijual dalam bentuk murni produk daur ulang maupun kombinasi dengan kertas atau karton dari pulp bahan alam. Karton daur ulang ini diduga dapat dimanfaatkan sebagai bahan pelapis papan komposit untuk meningkatkan sifat mekanisnya serta memperbaiki penampilan papan.

Penelitian ini ditujukan untuk mengetahui pengaruh jenis bahan pelapis dari karton daur ulang terhadap sifat fisis dan mekanis papan komposit. Sebagai pembanding, dibuat papan berlapis limbah karton gelombang dan papan tanpa lapisan.

\section{BAHAN DAN METODE}

\section{Persiapan Bahan}

Bahan yang digunakan berupa wafer dari jenis kayu sengon (Paraserianthes falcataria L Nielsen) (ukuran $2 \mathrm{~cm} \times 2 \mathrm{~cm} \times 2,25 \mathrm{~mm}$ ), karton, serta perekat water based polymer isocyanate 
(produksi PT Polychemie Asia Pacific Permai, Jakarta). Karton yang digunakan terdiri atas karton daur ulang (tebal 0,85 mm, gramatur $507 \mathrm{~g} / \mathrm{m}^{2}$ ), karton dupleks yang terbuat dari gabungan kertas daur ulang dan kertas kraft (tebal 0,60 mm, gramatur $471 \mathrm{~g} / \mathrm{m}^{2}$ ), dan limbah karton gelombang (tebal setelah dikempa 0,90 mm, gramatur 435 $\left.\mathrm{g} / \mathrm{m}^{2}\right)$.

\section{Pembuatan Papan}

Papan yang dibuat terdiri atas 5 jenis yaitu : papan berlapis karton dupleks, papan berlapis karton daur ulang tanpa perlakuan, papan berlapis karton daur ulang yang telah dicelup resin, papan berlapis karton gelombang, serta papan tanpa lapisan. Jumlah lapisan masing-masing 1 lembar untuk face dan back. Papan yang dibuat berukuran $30 \times 30 \mathrm{~cm}$ dengan tebal $1 \mathrm{~cm}$ serta kerapatan sasaran $0,65 \mathrm{~g} / \mathrm{cm}^{3}$.

Proses pembuatan papan diawali dengan pembuatan partikel berbentuk wafer dari kayu sengon dengan menggunakan disk flaker. Wafer kemudian dikeringudarakan dan dilanjutkan dengan pengeringan dalam tanur pada suhu $60^{\circ} \mathrm{C}$ untuk mencapai kadar air $2-4 \%$.

Lembaran karton dan kertas dipotong dengan ukuran $30 \mathrm{~cm} \times 30 \mathrm{~cm}$. Sebelum digunakan, karton gelombang dicelup dalam resin yang memiliki kadar padatan (solid content) 15\% selama 2 menit kemudian ditiriskan. Untuk menghilangkan gelombangnya, karton dikempa dingin selama 2 menit dengan tekanan $10 \mathrm{kgf} / \mathrm{cm}^{2}$ kemudian dikeringkan dalam tanur pada suhu $60^{\circ} \mathrm{C}$ selama 24 jam. Karton daur ulang digunakan dalam 2 tipe, yaitu digunakan langsung sebagai face dan back dan yang lainnya diberi perlakuan pencelupan dalam resin. Karton daur ulang dicelup resin selama 2 menit kemudian ditiriskan lalu dikeringkan dalam tanur bersama dengan karton gelombang. Karton dupleks digunakan langsung tanpa perlakuan.

Kadar perekat yang digunakan dalam pembuatan papan adalah $6 \%$ dari berat kering wafer dan bahan pelapis. Setelah ditimbang, wafer dimasukkan dalam blender lalu disemprot dengan perekat yang memiliki kadar padatan $20 \%$ dengan menggunakan spray gun. Pelaburan perekat pada lembaran face dan back dilakukan dengan menyemprotkan perekat pada permukaannya dengan berat resin cair rata-rata 2 g/lembar. Wafer yang telah tercampur perekat beserta bahan pelapis kemudian dicetak menjadi lembaran papan pada mesin kempa panas dengan suhu $130^{\circ} \mathrm{C}$, tekanan $24 \mathrm{kgf} / \mathrm{cm}^{2}$ selama 15 menit. Papan kemudian dikondisikan selama 14 hari sebelum dipotong menjadi contoh uji.

\section{Pengujian Kualitas Papan}

Pengujian kualitas papan dilakukan dengan mengamati parameter sifat fisis dan mekanisnya. Parameter sifat fisis yang diuji meliputi kerapatan, kadar air, daya serap air, pengembangan tebal, dan pengembangan linier, sementara parameter sifat mekanis yang diuji meliputi keteguhan patah (MOR), modulus elastisitas (MOE), serta keteguhan rekat (internal bond). Pengujian sifat fisis dan mekanis dilakukan berdasarkan standar JIS A 5908 - 1994.

\section{Analisis Data}

Penelitian ini dilakukan dengan menggunakan 5 ulangan untuk setiap jenis papan, sehingga jumlah keseluruhan papan sebanyak 25 lembar (5 Jenis). Kualitas papan dinilai dengan membandingkan hasil pengujian dengan JIS serta membandingkan kualitas papan antara satu dengan yang lain.

\section{HASIL DAN PEMBAHASAN}

\section{Kerapatan}

Berdasarkan hasil pengujian, nilai kerapatan papan berkisar dari 0,60 sampai $0,70 \mathrm{~g} / \mathrm{cm}^{3}$. Di dalam JIS 59081994 kerapatan papan ditetapkan sebesar 0,4 sampai $0,9 \mathrm{~g} / \mathrm{cm}^{3}$. Dengan demikian nilai kerapatan papan memenuhi standar tersebut. Perbandingan kerapatan untuk setiap jenis papan disajikan pada Gambar 1. Kerapatan merupakan salah satu indikator penting bagi kualitas papan komposit. Maloney (1993) menyatakan bahwa kerapatan sangat mempengaruhi kebanyakan sifat-sifat papan komposit. Peningkatan kerapatan akan memperbaiki hampir semua sifat papan komposit kecuali stabilitas dimensi. Kerapatan yang tinggi akan menghasilkan kontak yang intensif antara perekat dengan partikel sehingga penggunaan perekat lebih efisien.

\section{Kadar Air}

Hasil pengujian menunjukkan bahwa kadar air papan berkisar antara 6,39-9,28 \%. Di dalam JIS 5908 1994, nilai kadar air ditetapkan sebesar 5-13\%. Dengan demikian, seluruh papan yang dibuat memenuhi standar tersebut. Data nilai kadar air untuk setiap jenis papan disajikan 


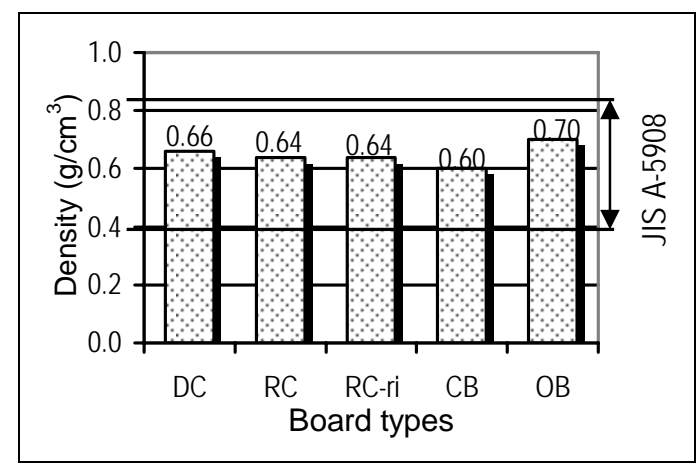

Legend:

DC : Board with duplex carton layers

RC : Board with recycled carton layers

RC-ri : Board with recycled and resin immersed carton layers

$\mathrm{CB} \quad$ : Board with corrugated board layers

$\mathrm{OB} \quad$ : Ordinary wafer board (without additional layer)

Figure 1. Histogram of board density

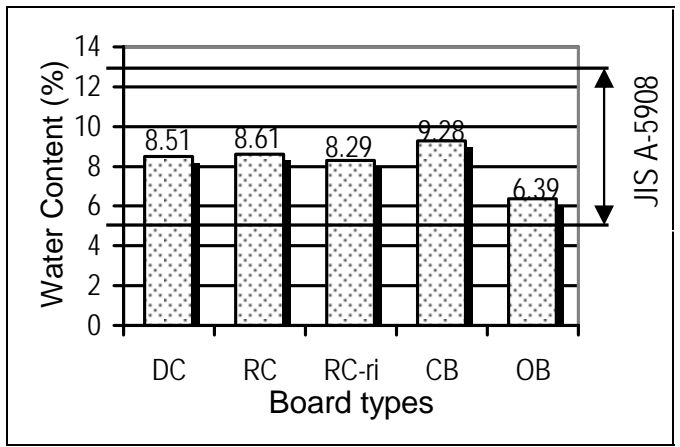

Legend: See Figure 1

Figure 2. Histogram of board water content

pada Gambar 2. Dari histogram pada gambar tersebut terlihat bahwa papan berlapis karton gelombang memiliki nilai kadar air paling tinggi $(9,28 \%)$ yang disebabkan oleh sifat karton gelombang yang relatif lebih mudah mengikat air dibanding jenis pelapis lainnya meskipun dikondisikan pada keadaan lingkungan yang sama.

\section{Daya Serap Air}

Daya serap air papan pada perendaman selama 2 jam berkisar antara 49,0 - 54,9\%, sementara pada perendaman selama 24 jam, daya serap air berkisar antara 84,2 - 95,0\%. Papan dengan pelapis karton daur ulang memiliki daya serap air terendah baik pada perendaman 2 jam maupun 24 jam, sementara nilai daya serap air

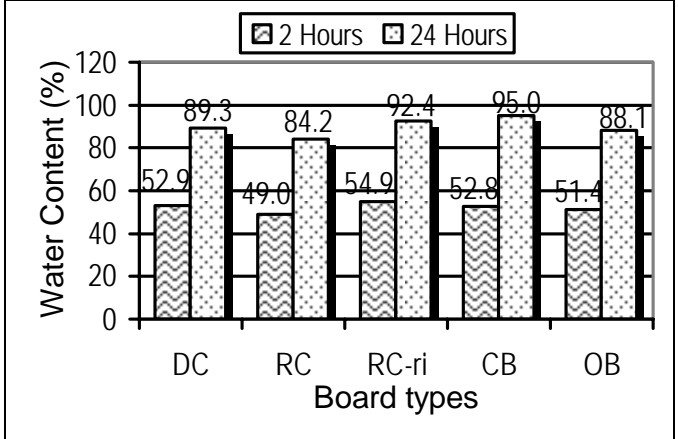

Legend: See Figure 1

Figure 3. Histogram of board water absorption

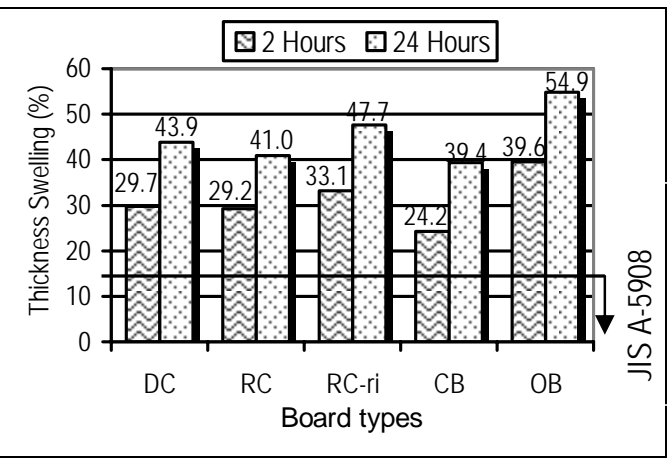

Legend: See Figure 1

Figure 4. Histogram of board thickness swelling

tertinggi pada perendaman 2 jam diperoleh dari papan dengan pelapis karton daur ulang yang dicelup resin. Adapun papan yang memiliki daya serap air tertinggi untuk perendaman 24 jam adalah papan dengan pelapis karton gelombang. Nilai daya serap air masing-masing jenis papan disajikan pada Gambar 3.

\section{Pengembangan Tebal}

Histogram pada Gambar 4 menunjukkan bahwa nilai pengembangan tebal seluruh jenis papan tidak memenuhi JIS A 59081994 baik untuk tipe papan berlapis finir (maks. 12\%) maupun tipe wafer board (maks. 20\%). Nilai pengembangan tebal yang tinggi antara lain disebabkan oleh tingginya compression ratio dalam pembuatan papan ini. Dengan kerapatan rata-rata bahan baku sebesar $0,36 \mathrm{~g} / \mathrm{cm}^{3}$ serta kerapatan papan berkisar antara 0,6-0,7 $\mathrm{g} / \mathrm{cm}^{3}$ maka compression ratio berkisar antara 1,7 sampai 1,9. Maloney (1993) menyatakan bahwa compression ratio yang optimal adalah 1,3. Compression ratio yang tinggi akan meningkatkan sifat mekanis papan, tetapi di sisi lain akan menurunkan stabilitas dimensi. 


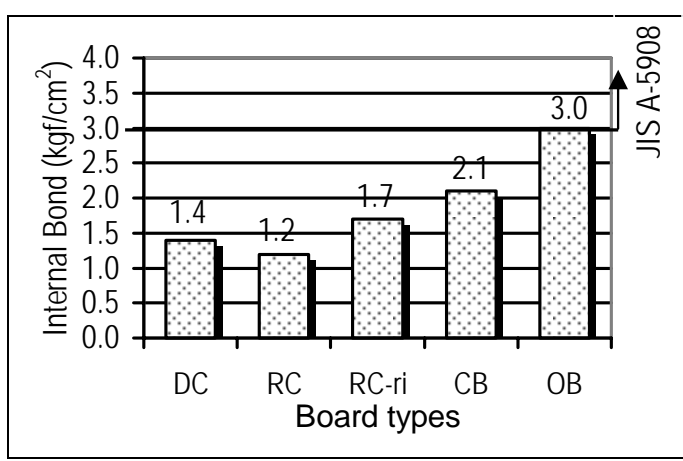

Legend: See Figure 1

Figure 5. Histogram of board internal bond

\section{Keteguhan Rekat}

Hasil pengujian menunjukkan bahwa nilai keteguhan rekat papan berkisar dari 1,2 - 3,0 $\mathrm{kgf} / \mathrm{cm}^{2}$. Nilai internal bond untuk setiap jenis papan disajikan pada Gambar 5. Dari 5 jenis papan yang dibuat, hanya papan tanpa lapisan yang memiliki nilai keteguhan rekat yang memenuhi standar JIS. Pengujian keteguhan rekat dengan cara memberikan gaya tarik secara berlawanan pada arah tegak lurus permukaan papan akan menimbulkan kerusakan pada bagian terlemah papan. Pada jenis papan tanpa lapisan, ikatan terlemah terdapat pada bagian core. Fenomena ini merupakan hal yang umum pada papan komposit 1 lapis dimana terjadi penurunan gradasi kerapatan dari permukaan ke bagian tengah papan yang berimplikasi pada lemahnya ikatan yang terbentuk antara partikel dengan perekat. Pada jenis papan yang tidak memenuhi standar, ikatan dalam karton pelapis lebih lemah dari ikatan pada core papan. Dengan demikian sebelum ikatan perekat pada bagian core rusak, ikatan antar bagian karton telah lebih dahulu mengalami kerusakan. Karton dupleks dan karton daur ulang pada dasarnya tersusun dari lembaran kertas tipis yang digabung satu sama lain, sehingga pada saat terjadi gaya tarik, ikatan antar lembaran ini mengalami kerusakan terlebih dahulu.

\section{Keteguhan Patah (MOR)}

Keteguhan patah (MOR) papan pada sejajar arah panjang papan berkisar antara 177 $258 \mathrm{kgf} / \mathrm{cm}^{2}$, sementara pada tegak lurus arah panjang papan berkisar antara 165 - $246 \mathrm{kgf} / \mathrm{cm}^{2}$. Nilai keteguhan patah masing-masing jenis papan disajikan pada Gambar 6.

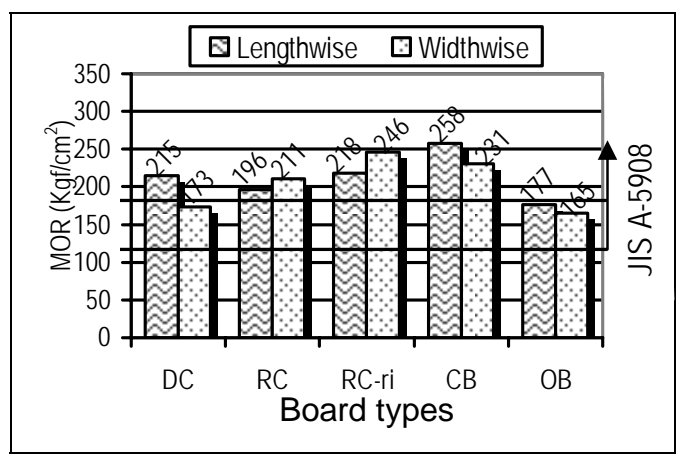

Legend: See Figure 1

Figure 6. Histogram of board MOR

Berdasarkan standar JIS, nilai MOR seluruh jenis papan yang dibuat tidak memenuhi standar pada searah panjang papan untuk tipe papan berlapis finir (minimal $306 \mathrm{kgf} / \mathrm{cm}^{2}$ ), namun jenisjenis papan tersebut memenuhi standar untuk tipe wafer board. Namun demikian, pada tegak lurus arah panjang papan, seluruh jenis papan yang dibuat memenuhi standar baik untuk tipe papan berlapis finir (minimal $153 \mathrm{kgf} / \mathrm{cm}^{2}$ ) maupun tipe wafer board (minimal $107 \mathrm{kgf} / \mathrm{cm}^{2}$ ).

Gambar 6 juga menunjukkan bahwa pemberian bahan pelapis pada papan komposit mampu meningkatkan nilai MOR papan. Nilai MOR terbaik diperoleh pada papan berlapis limbah karton gelombang. Nilai MOR cukup tinggi juga diperoleh dari papan berlapis karton daur ulang yang dicelup resin. Hal Ini mengindikasikan bahwa pencelupan karton daur ulang dalam resin dapat meningkatkan kekuatan karton yang berperan terhadap peningkatan nilai MOR papan.

\section{Modulus Elastisitas (MOE)}

Nilai modulus elastisitas (MOE) papan pada sejajar arah panjang papan berkisar antara 1,3$1,9 \times 10^{4} \mathrm{kgf} / \mathrm{cm}^{2}$, sementara pada tegak lurus arah panjang papan berkisar antara 1,4 - 1,6 x 104 $\mathrm{kgf} / \mathrm{cm}^{2}$. Niliai MOE masing-masing jenis papan disajikan pada Gambar 7.

Berdasarkan JIS A 5908, nilai MOE papan berlapis finir pada sejajar arah panjang papan minimal 4,59 x $10^{4} \mathrm{kgf} / \mathrm{cm}^{2}$, sementara pada arah tegak lurus minimal 2,86 × $10^{4} \mathrm{kgf} / \mathrm{cm}^{2}$. Sedangkan nilai MOE wafer board pada sejajar arah panjang papan minimal 3,06 x $10^{4} \mathrm{kgf} / \mathrm{cm}^{2}$, sementara pada arah tegak lurus minimal 2,04 x $10^{4} \mathrm{kgf} / \mathrm{cm}^{2}$. Dengan demikian dari keseluruhan papan yang dibuat, tidak ada jenis papan yang memenuhi standar. Data tersebut juga menunjukkan bahwa pemberian bahan pelapis hanya meningkatkan 


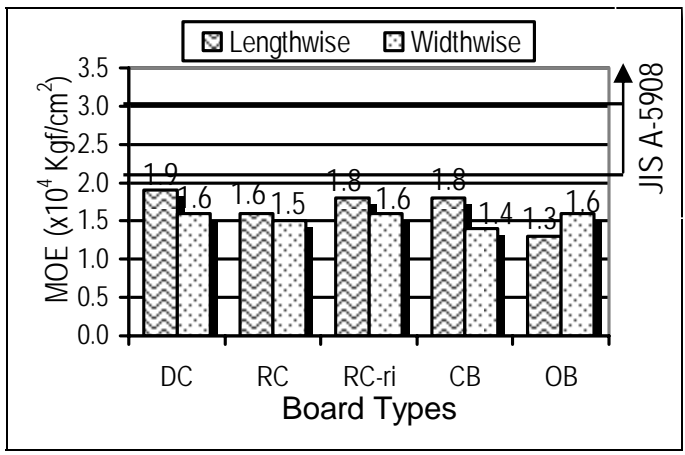

Legend: See Figure 1

Figure 7. Histogram of board MOE

nilai MOE pada sejajar arah panjang papan, sementara pada tegak lurus arah panjang papan tidak memberikan pengaruh yang berarti.

\section{Perbandingan Kualitas Papan Komposit}

Hasil analisis sifat fisis dan mekanis kelima jenis papan komposit menunjukkan bahwa terdapat perbedaan sifat yang signifikan di antara jenis-jenis papan tersebut. Namun demikian, tidak ada papan yang memiliki sifat terbaik pada semua parameter yang diuji.

Papan komposit berlapis karton gelombang memiliki stabilitas dimensi yang terbaik dibanding jenis papan lainnya, sementara papan tanpa lapisan memiliki stabilitas dimensi paling rendah. Fakta ini mengindikasikan bahwa pemberian bahan pelapis memberikan pengaruh yang positif terhadap stabilitas dimensi papan. Pengaruh yang sama juga ditunjukkan pada kekuatan patah papan, dimana seluruh jenis bahan pelapis yang digunakan mampu meningkatkan kekuatan patah papan. Kekuatan patah terbaik diperoleh pada papan dengan bahan pelapis limbah karton gelombang. Kekuatan patah yang cukup tinggi juga diperoleh pada papan berlapis karton daur ulang yang dicelup resin. Fenomena yang sama juga diperoleh pada parameter modulus elastisitas, namun demikian peningkatannya hanya terjadi pada sejajar arah panjang papan sementara pada tegak lurus arah panjang papan tidak memberikan pengaruh yang berarti. Fenomena yang berbeda terjadi pada parameter keteguhan rekat internal dimana pemberian bahan pelapis justru menurunkan keteguhan rekat papan. Hal tersebut terjadi karena karton yang pada dasarnya tersusun dari lembaran-lembaran kertas tipis memiliki ikatan yang lebih lemah dibanding ikatan antar partikel kayu.

\section{KESIMPULAN}

Dari hasil pengujian papan komposit dengan beberapa jenis pelapis face dan back, dapat disimpulkan bahwa jenis bahan pelapis berpengaruh terhadap kualitas papan komposit, dan secara umum pemberian lapisan karton sebagai bahan substitusi finir dapat memperbaiki sifat fisis dan mekanis papan komposit. Parameter sifat fisis papan komposit tersebut yang memenuhi standar JIS adalah kadar air dan kerapatan, sementara pengembangan tebal tidak memenuhi standar. Nilai keteguhan patah papan komposit memenuhi standar JIS pada tipe wafer board, tetapi tidak memenuhi standar untuk tipe papan berlapis finir. Dari seluruh papan yang dibuat, tidak ada jenis papan yang memenuhi standar JIS untuk parameter modulus elastisitas, sementara untuk parameter keteguhan rekat internal hanya jenis papan tanpa lapisan yang memenuhi standar.

\section{DAFTAR PUSTAKA}

[JSA] Japanese standards association, 1994. Particleboards. Japanese industrial standar (JIS) A 5908-1994. Japan.

Hayashi K, M Ohmi, H Tominaga, and K Fukuda, 2003. Effect of board density on bending properties and dimensional stabilities of MDFreinforced corrugated particleboard. Japan : J. Wood Sci. 49 (5) : 398 -404.

Maloney, T. M., 1993. Modern particleboard and dry-process fiberboard manufacturing. Revised edition. USA : Miller Freeman Inc San Francisco.

Mansur, H. M., 2002. Present condition and prospect of pulp and paper industry in Indonesia. In : Proceeding of the International Wood Science Symposium. JSPS-LIPI Core University Program; Serpong, 2 - 5 September 2002. pp 5-9

Massijaya, M. Y., 1997. Development of boards made from waste newspaper [Ph.D. Dissertation, unpublished]. Tokyo Japan : Tokyo University.

, 2003. Pemanfaatan limbah kayu dan karton sebagai bahan baku papan komposit : Sifat-sifat dasar dan teknik pembuatan papan komposit dari limbah kayu dan karton. Bogor : Laporan Penelitian Hibah Bersaing XI/I Perguruan Tinggi Tahun Anggaran 2003.

Sudijono, and Subyakto, 2002. Bending and shear properties of low density particleboard 
laminated with Zephyr of tali bamboo. in : Proceeding of the International Wood Science Symposium. JSPS-LIPI Core University
Program; Serpong, 2 - 5 September 2002. pp $219-222$.

Diterima tanggal : 15 Desember 2005

\author{
Suhasman \\ Laboratorium Wood Working \\ Jurusan Kehutanan Universitas Hasanuddin \\ Kampus Unhas Tamalanrea, Makassar - 90245 \\ Telp. (0411) 585917 \\ E-mail : suhasman@yahoo.com \\ Muh. Yusram Massijaya dan Yusuf Sudo Hadi \\ Laboratorium Bio-komposit \\ Departemen Hasil Hutan Fak. Kehutanan IPB \\ Kampus Darmaga - Bogor
}

